\title{
Preparation and Characterization of Water-Soluble Chitosan Nanoparticles as Protein Delivery System
}

\author{
Hong-liang Zhang, ${ }^{1}$ Si-hui Wu, ${ }^{1}$ Yi Tao, ${ }^{1}$ Lin-quan Zang, ${ }^{1}$ and Zheng-quan Su${ }^{2}$ \\ ${ }^{1}$ College of Pharmacy, Guangdong Pharmaceutical University, Guangzhou 510006, China \\ ${ }^{2}$ College of Public Health, Guangdong Pharmaceutical University, Guangzhou 510240, China
}

Correspondence should be addressed to Zheng-quan Su, suzhq@scnu.edu.cn

Received 6 July 2009; Revised 1 September 2009; Accepted 1 November 2009

Academic Editor: Gaurav Mago

Copyright ( 2010 Hong-liang Zhang et al. This is an open access article distributed under the Creative Commons Attribution License, which permits unrestricted use, distribution, and reproduction in any medium, provided the original work is properly cited.

\begin{abstract}
The objective of this study was to investigate the potential of water soluble chitosan as a carrier in the preparation of protein-loaded nanoparticles. Nanoparticles were prepared by ionotropic gelation of water-soluble chitosan (WSC) with sodium tripolyphosphate (TPP). Bovine serum albumin (BSA) was applied as a model drug. The size and morphology of the nanoparticles were investigated as a function of the preparation conditions. The particles were spherical in shape and had a smooth surface. The size range of the nanoparticles was between 100 and $400 \mathrm{~nm}$. Result of the in vitro studies showed that the WSC nanoparticles enhance and prolong the intestinal absorption of BSA. These results also indicated that WSC nanoparticles were a potential protein delivery system.
\end{abstract}

\section{Introduction}

Peptides and proteins have become the drugs of choice for the treatment of numerous diseases as a result of their incredible selectivity and their ability to provide effective and potent action [1]. In general, they cause fewer side effects and have great potential to cure diseases, rather than merely treat their symptoms. The successful delivery of these protein drugs has been an ongoing topic in the pharmaceutical research for many years. Among various delivery methods, the oral delivery is the most convenient and desired way of drug delivery, especially when repeated or routine administration is concerned [2]. However, protein and peptide drugs are poorly absorbed after oral administration because of their susceptibility to enzymatic degradation and their low permeability across the intestinal epithelium. Various approaches have been proposed to overcome barriers and to attain better oral bioavailability, including the use of surfactants, permeation enhancers, protease inhibitors, enteric coatings, and carrier systems [3, 4]. Amongst these, the use of colloidal polymeric particulate delivery systems, particularly mucoadhesive nanoparticles, represents a promising concept $[5,6]$.
Nanoparticles have received much attention for the delivery of macromolecular drugs, such as peptides, proteins, and genes, due to their ability to protect protein and peptides from degradation in the gastrointestinal track by proteolytic enzymes [7-9]. Nanoparticles possess marked mucoadhesion properties that have been related to the combination of the particle size and the particle superficial charge. Furthermore nanoparticles have been referred to as capable of being absorbed into mucosal tissue.

Chitosan received attention as a material for nanoparticles for the decade [10]. Chitosan is a well-known natural cationic polyelectrolyte. It is a partially deacetylated form of chitin, which is a structural polysaccharide found in crustacea, insects, and some fungi, and it has attracted interest as a biocompatible, biodegradable, mucoadhesive, and nontoxic material for use in biomedical applications [11-14]. In addition, chitosan has a special feature of adhering to the mucosal surface and transiently opening the tight junction between epithelial cells [15]. Thus, chitosan nanoparticles are potential delivery system for hydrophilic drugs due to its outstanding physicochemical and biological properties. 
Despite of its superiority as a biomaterial, chitosan is not fully soluble in water and then soluble in acidic solution. Aqueous solubility of chitosan only in acidic solution because of its rigid crystalline structure and the deacetylation which limits its application to bioactive agents such as gene delivery carriers, peptide carriers, and drug carriers. Watersoluble chitosan is easily soluble in neutral aqueous solution. Its advantage is ease of modification, useful as gene or peptide drug carriers. Therefore, water-soluble chitosan and functional property have been developing for pharmaceutical and new drug candidate.

Therefore, the major goal of the present study is to create a kind of new biodegradable nanoparticle as protein delivery system. The nanoparticles have been characterized in terms of size, polydispersity index, and association efficiency. Also in vitro release was investigated to determine the efficacy of this system and the effective factors on absorption via this system.

\section{Materials and Methods}

2.1. Material. WSC (degree of deacetylation $87 \%$, molecular weight $21 \mathrm{kDa}$ ) was made from a shrimp shell and obtained from Shandong Aokang Biotech Ltd. (Shandong, China). BSA with Mw $68 \mathrm{kDa}$ and Coomassie brilliant blue G250 were purchased from Sigma Chemical Co. (USA). All other reagents and solvents were of analytical grade.

\subsection{Preparation of Chitosan Nanoparticles and BSA-Loaded} Nanoparticles. WSC-BSA nanoparticles were prepared by methods adapted from that reported by Calvo et al. [16]. Briefly, WSC was dissolved in aqueous solution at different concentration. Then, tripolyphosphate (TPP) was dissolved in distilled water at $1.0 \mathrm{mg} / \mathrm{mL}$. Nanoparticles were spontaneously obtained upon the addition of $1 \mathrm{~mL}(1 \mathrm{mg} / \mathrm{mL}$, $\mathrm{w} / \mathrm{v}$ ) of a TPP aqueous basic solution to $5 \mathrm{~mL}$ of the chitosan aqueous solution $(1 \mathrm{mg} / \mathrm{mL}, \mathrm{w} / \mathrm{v})$ under magnetic stirring at room temperature. BSA-loaded nanoparticles were formed by the addition of $1 \mathrm{~mL}$ BSA solution to chitosan solution prior to the incorporation of TPP solution. The detailed formation conditions were shown in the corresponding figures. The factors tested included BSA initial concentration $(0.1,0.2,0.5,1.0 \mathrm{mg} / \mathrm{mL})$ and chitosan concentration $(0.5,1.0,1.5,2.0,3.0 \mathrm{mg} / \mathrm{mL})$. When we evaluated one factor, we only altered its own parameters and kept the parameters of other factors constant. Without specific depiction, the parameters of chitosan were as follows: concentration $1.0 \mathrm{mg} / \mathrm{mL}, \mathrm{DD} 96 \%$, and $\mathrm{Mw}$ $210 \mathrm{kDa}$; initial concentration of BSA was $0.5 \mathrm{mg} / \mathrm{mL}$; TPP concentration was $1.0 \mathrm{mg} / \mathrm{mL}$. The nanoparticles are characterized immediately. All experiments were performed in triplicates.

2.3. Characterization of Nanoparticles. The particle size and size distributions of the nanoparticles were performed by particle sizer (Zetasizer 3000 HAS, Malvern Instruments Ltd., Worcs, UK). Chitosan nanoparticles separated from suspension were dried by a freeze dryer; their FTIRs (Shimadzu, FT-IR 8700, Japan) were taken with $\mathrm{KBr}$ pellets on Perkin-Elmer Spectrum one FTIR.

2.4. Determination of BSA Encapsulation Efficiency of Nanoparticles. To determine the encapsulation efficiency and loading capacity, nanoparticles with the different formation were centrifuged at $15,000 \times r$ and $4^{\circ} \mathrm{C}$ for 30 minutes, and the amount of free BSA was determined in clear supernatant by UV spectrophotometry (ShimadzuUV1601, Shimadzu Co. Ltd., Japan) at $595 \mathrm{~nm}$ using supernatant of nonloaded nanoparticles as basic correction. BSA encapsulation efficiency (AE) and loading capacity (LC) were calculated according to (1) indicated below:

$$
\begin{aligned}
& \mathrm{AE}=\frac{\text { Total amount BSA }- \text { Free amount BSA }}{\text { Total amount BSA }}, \\
& \mathrm{LC}=\frac{\text { Total amount BSA }- \text { Free amount BSA }}{\text { Nanoparticles weight }} .
\end{aligned}
$$

2.5. In Vitro Release Study. BSA release from chitosan nanoparticles was determined as follows. A known amount of freeze-dried nanoparticles was transferred to a $25 \mathrm{~mL}$ tube and $10 \mathrm{~mL}$ of the respective dissolution buffer was added to the tube. The temperature and rotation were adjusted to $37^{\circ} \mathrm{C}$ and $90 \mathrm{rpm}$, respectively. At predetermined time of $0.5,2,4,6,8,10,12$, and 24 hour $5 \mathrm{~mL}$ of sample was removed and ultracentrifuged at $15,000 \times r$ for 30 minutes, and $5 \mathrm{~mL}$ of the supernatant were replaced by fresh medium. The samples were further analyzed using UV.

\section{Results and Discussion}

3.1. Physicochemical Characterizations of Nanoparticles. The structure of BSA-loaded lyophilized nanoparticles was examined by TEM (Tokyo, Japan). They showed that the particles have a uniform spherical shape and smooth surface (Figure 1(b)), and they are about $150 \mathrm{~nm}$ in size (Figure 1(a)). FTIR spectra of WSC nanoparticles and WSC matrix are shown in Figure 2. A band at $3420 / \mathrm{cm}$ has been previously attributed to $-\mathrm{NH}_{2}$ and $-\mathrm{OH}$ group stretching vibration in WSC matrix [17]. In WSC nanoparticles a shift from 3420 to $3430 / \mathrm{cm}$ is shown, and the peak of $3430 / \mathrm{cm}$ becomes wider; this indicates that hydrogen bonding is enhanced. In nanoparticles a new sharp peak $1638 / \mathrm{cm}$ appears, and the $1630 / \mathrm{cm}$ peak of $-\mathrm{NH}_{2}$ bending vibration shifts to $1645 / \mathrm{cm}$. Knaul observed the similar result in the study of chitosan film treated with phosphate $\left(\mathrm{NaH}_{2} \mathrm{PO}_{4}\right)$ and attributed it to the linkage between phosphoric and ammonium ion [18]. So we suppose that the tripolyphosphoric groups of TPP are linked with ammonium group of WSC; the inter- and intramolecular action are enhanced in chitosan nanoparticles. 


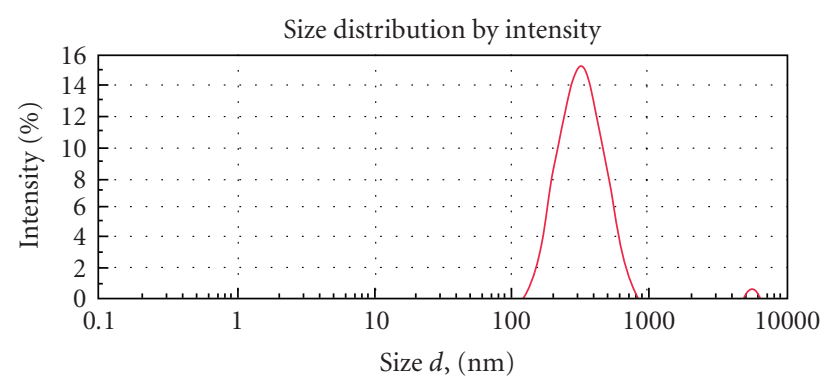

- Record 2:02

(a)

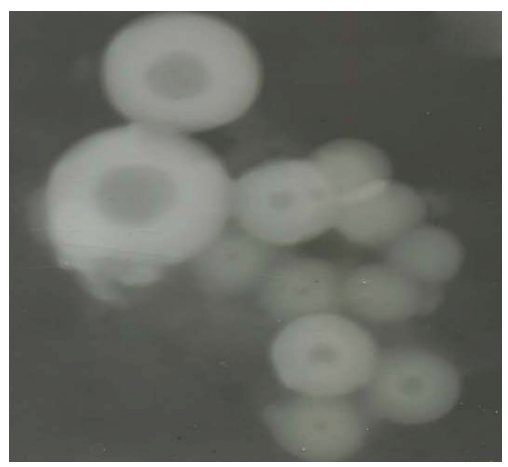

(b)

Figure 1: (a) Particle size distribution of WSC nanoparticles. (b) TEM image of WSC nanoparticles.

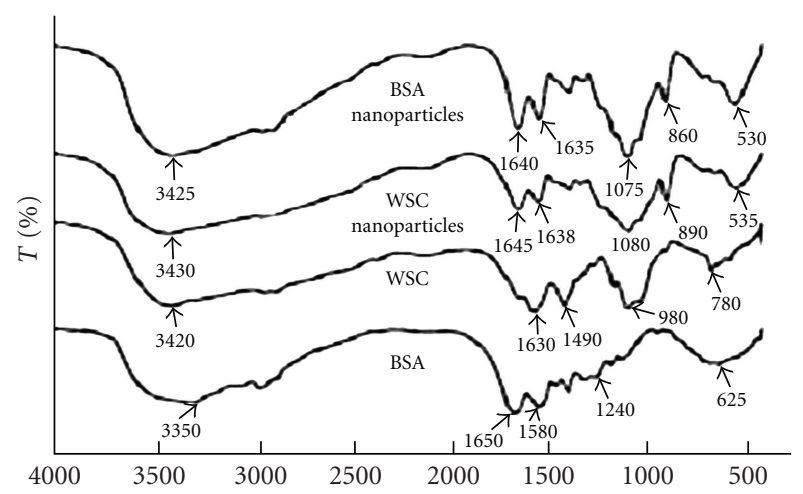

FIGURE 2: FTIR of BSA nanoparticles, WSC nanoparticles, WSC and BSA.

\subsection{Encapsulation Efficiency}

3.2.1. Effect of BSA Concentration. In most nanoparticle delivery systems, the drug carrying capacity is defined as an encapsulation efficiency. In the present study, BSA was carried on the nanoparticles via the ionic interaction. In water, the long hydrophilic chains extended to the water, and some BSA might be encapsulated among the positive hydrophilic chains, which indicated that the BSA was not only on the surface of the nanoparticles but also was distributed in the outer hydrophilic area. So, the BSA carrying capacity of the nanoparticles could be termed as encapsulation efficiency. In this study, BSA encapsulation efficiency from $40 \%$ to $95 \%$

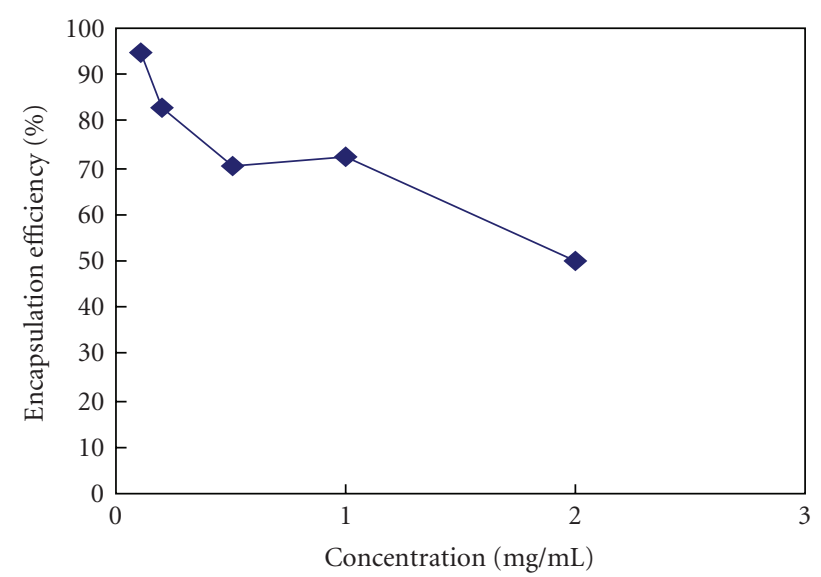

Figure 3: The influence of BSA initial concentration on encapsulation efficiency (WSC $1 \mathrm{mg} / \mathrm{mL}$, TPP $1 \mathrm{mg} / \mathrm{mL}, n=5$ ).

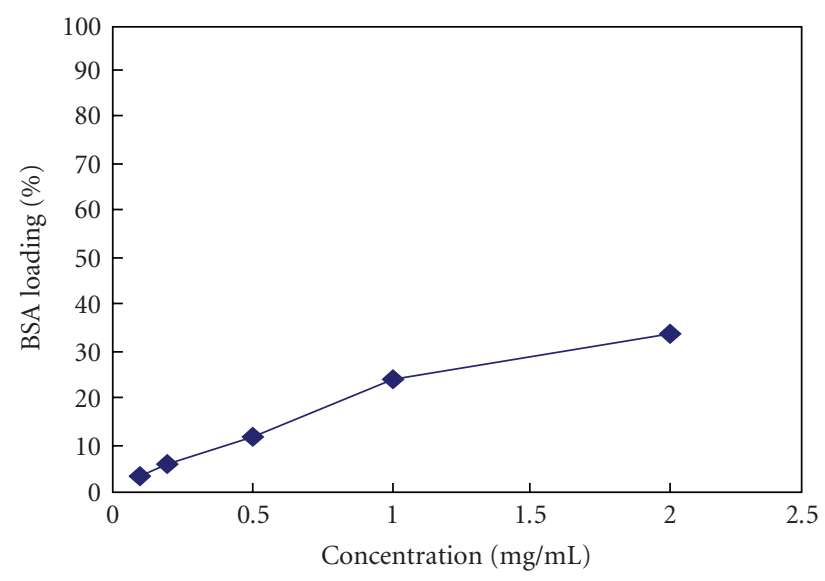

FIgure 4: The influence of BSA initial concentration on loading capacity (WSC $1 \mathrm{mg} / \mathrm{mL}$, TPP $1 \mathrm{mg} / \mathrm{mL}, n=5$ ).

was significantly affected by the initial BSA concentration in Figure 3; the lower the concentration, the higher the encapsulation efficiency. However, the protein loading was enhanced dramatically from $5 \%$ to $30 \%$ by increasing the initial BSA concentration from 0.1 to $2 \mathrm{mg} / \mathrm{mL}$ in Figure 4 .

3.2.2. Effect of Chitosan Concentration. When TPP concentration was $1 \mathrm{mg} / \mathrm{mL}$, decreasing chitosan concentration down to $0.5 \mathrm{mg} / \mathrm{mL}$, aggregates with large diameter were formed; increasing chitosan concentration up to $4 \mathrm{mg} / \mathrm{mL}$ made encapsulation extremely difficult. Formation of nanoparticles is only possible for some specific concentration of chitosan and TPP. As for gelation between TPP solution of $1 \mathrm{mg} / \mathrm{mL}$ and chitosan solution of $1-3 \mathrm{mg} / \mathrm{mL}$, we usually observed that some opalescent suspension was formed, which was examined as nanoparticles. Adding TPP solution of $1 \mathrm{mg} / \mathrm{mL}$ to chitosan solution of $4 \mathrm{mg} / \mathrm{mL}$, firstly we observed some opalescent suspension and then disappeared immediately, and the nanoparticles formation was extremely difficult. Figure 5 shows that increasing the chitosan concentration decreased encapsulation efficiency of 


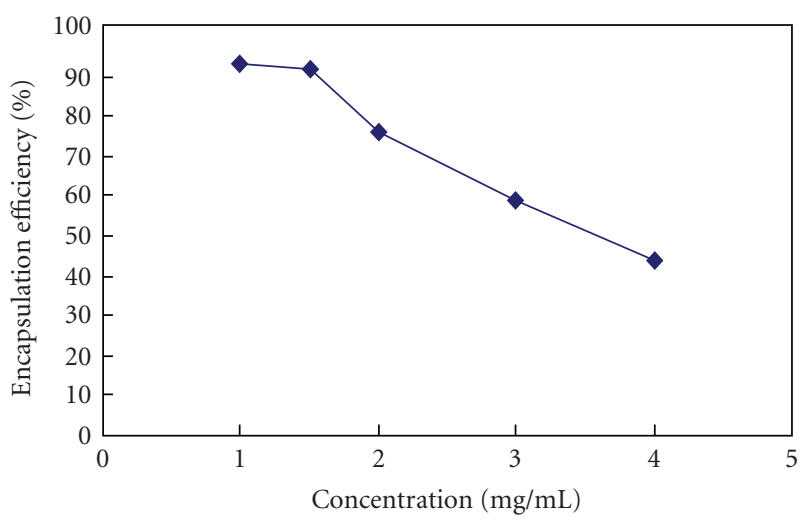

FIgURE 5: The influence of chitosan concentration on BSA encapsulation efficiency (BSA $0.5 \mathrm{mg} / \mathrm{mL}$, TPP $1 \mathrm{mg} / \mathrm{mL}, n=5$ ).

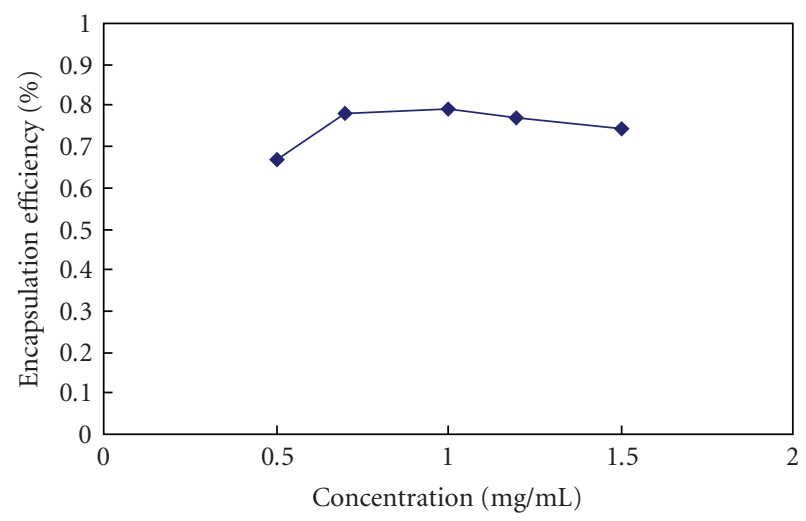

FIgURE 6: The influence of TPP concentration on BSA encapsulation efficiency (WSC $1 \mathrm{mg} / \mathrm{mL}$, BSA $0.5 \mathrm{mg} / \mathrm{mL}, n=5$ ).

BSA. Vandenberg stated that the highly viscous nature of the gelation medium hinders encapsulation of BSA in the study of chitosan-alginate microspheres [19]. Relatively lower adhesiveness of chitosan with lower concentration promotes encapsulation of BSA and gelation between chitosan and TPP.

3.2.3. Effect of TPP Concentration. Many studies have reported that the quantity of TPP in a given formulation has a significant effect on the protein encapsulation and characteristic of NP $[20,21]$. Therefore, the optimal amount of TPP in formulation was investigated in detail. As concluded in Figure 6 encapsulation efficiency of the nanoparticles was affected by the TPP solution, with increasing amount ratio of TPP to chitosan leading to a slight change of encapsulation efficiency. When WSC concentration was $1 \mathrm{mg} / \mathrm{mL}$, BSA concentration was $0.5 \mathrm{mg} / \mathrm{mL}$; decreasing TPP concentration down to $0.5 \mathrm{mg} / \mathrm{mL}$, aggregates with large diameter were formed; increasing TPP concentration up to $2 \mathrm{mg} / \mathrm{mL}$ made encapsulation extremely difficult.

On the basis of above result, TPP did not affect the entrapment efficiency of BSA-chitosan nanoparticles when nanoparticles were formed at optimal chitosan/BSA mass of $1: 0.5$. Therefore, it is reasonable to assume

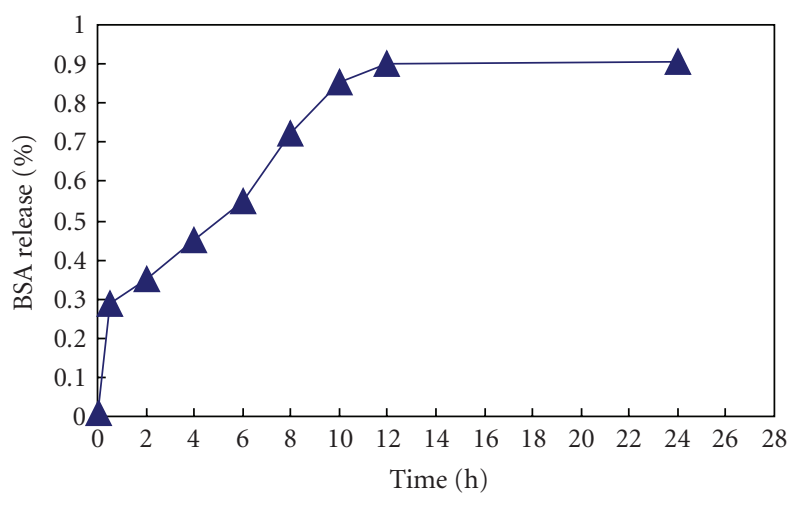

Figure 7: BSA release (WSC $1 \mathrm{mg} / \mathrm{mL}$, BSA $0.5 \mathrm{mg} / \mathrm{mL}$, TPP $1 \mathrm{mg} / \mathrm{mL}$ ).

that polymer/BSA charge ratio plays an important role in nanoparticles formation.

3.3. In Vitro Release. The preliminary protein release test from BSA nanoparticles in vitro proves that they have a sustained release form as shown in Figure 7. Ionic strength in release medium may affect significantly the release properties of BSA nanoparticles based on ionic gelation; so we choose phosphate buffer ( $\mathrm{pH}$ 7.4) as release medium which simulates body fluid according to literatures [22]. The in vitro protein release profiles obtained for each formulation showed three phases compositions [23]:

(1) a first initial burst release of $30 \%$, due to the drug desorbed from the particles surface,

(2) a plateau for the following $8 \mathrm{~h}$, resulting from the only diffusion of the drug dispersed in the polymermatrix,

(3) a constant sustained release of the drug, resulting from the diffusion of the protein through the polymer wall as well as its erosion.

\section{Conclusion}

In summary, novel ionic crosslinking nanoparticles composed of WSC and TPP loaded with BSA were successfully prepared. The size distribution was in the range of $200-$ $400 \mathrm{~nm}$. The nanoparticles were spherical shape and smooth surface. WSC nanoparticles showed higher protein encapsulation efficiency. In addition, the BSA release from the nanoparticles was sustained release. Therefore, WSCs have a potential carrier in a controlled drug delivery system for protein drugs.

\section{References}

[1] S. Frokjaer and D. E. Otzen, "Protein drug stability: a formulation challenge," Nature Reviews Drug Discovery, vol. 4, no. 4, pp. 298-306, 2005.

[2] B.-Y. Kim, J. H. Jeong, K. Park, and J.-D. Kim, "Bioadhesive interaction and hypoglycemic effect of insulin-loaded lectinmicroparticle conjugates in oral insulin delivery system," Journal of Controlled Release, vol. 102, no. 3, pp. 525-538, 2005. 
[3] G. P. Carino, J. S. Jacob, and E. Mathiowitz, "Nanosphere based oral insulin delivery," Journal of Controlled Release, vol. 65, no. 1-2, pp. 261-269, 2000.

[4] K. Nakashima, M. Miyagi, K. Goto, Y. Matsumoto, and R. Ueoka, "Enzymatic and hyperglycemia stability of chemically modified insulins with hydrophobic acyl groups," Bioorganic and Medicinal Chemistry Letters, vol. 14, no. 2, pp. 481-483, 2004.

[5] G. Ponchel and J.-M. Irache, "Specific and non-specific bioadhesive particulate systems for oral delivery to the gastrointestinal tract," Advanced Drug Delivery Reviews, vol. 34, no. 2-3, pp. 191-219, 1998.

[6] H. Takeuchi, H. Yamamoto, and Y. Kawashima, "Mucoadhesive nanoparticulate systems for peptide drug delivery," Advanced Drug Delivery Reviews, vol. 47, no. 1, pp. 39-54, 2001.

[7] S. Sakuma, M. Hayashi, and M. Akashi, "Design of nanoparticles composed of graft copolymers for oral peptide delivery," Advanced Drug Delivery Reviews, vol. 47, no. 1, pp. 21-37, 2001.

[8] B. Sarmento, D. C. Ferreira, L. Jorgensen, and M. van de Weert, "Probing insulin's secondary structure after entrapment into alginate/chitosan nanoparticles," European Journal of Pharmaceutics and Biopharmaceutics, vol. 65, no. 1, pp. 10-17, 2007.

[9] F. Chen, Z.-R. Zhang, and Y. Huang, "Evaluation and modification of N-trimethyl chitosan chloride nanoparticles as protein carriers," International Journal of Pharmaceutics, vol. 336, no. 1, pp. 166-173, 2007.

[10] K. A. Janes, P. Calvo, and M. J. Alonso, "Polysaccharide colloidal particles as delivery systems for macromolecules," Advanced Drug Delivery Reviews, vol. 47, no. 1, pp. 83-97, 2001.

[11] W. Paul and C. P. Sharma, "Chitosan, a drug carrier for the 21st century: a review," S.T.P. Pharma Sciences, vol. 10, no. 1, pp. 5-22, 2000.

[12] M. Thanou, J. C. Verhoef, and H. E. Junginger, "Oral drug absorption enhancement by chitosan and its derivatives," Advanced Drug Delivery Reviews, vol. 52, no. 2, pp. 117-126, 2001.

[13] X. Z. Shu and K. J. Zhu, "Controlled drug release properties of ionically cross-linked chitosan beads: the influence of anion structure," International Journal of Pharmaceutics, vol. 233, no. 1-2, pp. 217-225, 2002.

[14] E. Khor and L. Y. Lim, "Implantable applications of chitin and chitosan," Biomaterials, vol. 24, no. 13, pp. 2339-2349, 2003.

[15] F. Qian, F. Cui, J. Ding, C. Tang, and C. Yin, "Chitosan graft copolymer nanoparticles for oral protein drug delivery: preparation and characterization," Biomacromolecules, vol. 7, no. 10, pp. 2722-2727, 2006.

[16] P. Calvo, C. Remuñán-López, J. L. Vila-Jato, and M. J. Alonso, "Novel hydrophilic chitosan-polyethylene oxide nanoparticles as protein carriers," Journal of Applied Polymer Science, vol. 63, no. 1, pp. 125-132, 1997.

[17] J.-H. Yu, Y.-M. Du, and H. Zheng, "Blend films of chitosangelatin," Wuhan University Journal of Natural Sciences, vol. 45, no. 4, pp. 440-444, 1999.

[18] J. Z. Knaul, S. M. Hudson, and K. A. M. Creber, "Improved mechanical properties of chitosan fibers," Journal of Applied Polymer Science, vol. 72, no. 13, pp. 1721-1732, 1999.

[19] R. J. Vandenberg and K. R. Aubrey, "Glycine transport inhibitors as potential antipsychotic drugs," Expert Opinion on Therapeutic Targets, vol. 5, no. 4, pp. 507-518, 2001.

[20] K. A. Janes and M. J. Alonso, "Depolymerized chitosan nanoparticles for protein delivery: preparation and characterization," Journal of Applied Polymer Science, vol. 88, no. 12, pp. 2769-2776, 2003.

[21] A. Grenha, B. Seijo, and C. Remuñán-López, "Microencapsulated chitosan nanoparticles for lung protein delivery," European Journal of Pharmaceutical Sciences, vol. 25, no. 4-5, pp. 427-437, 2005.

[22] E. Leo, R. Cameroni, and F. Forni, "Dynamic dialysis for the drug release evaluation from doxorubicin-gelatin nanoparticle conjugates," International Journal of Pharmaceutics, vol. 180, no. 1, pp. 23-30, 1999.

[23] A. Lamprecht, N. Ubrich, M. H. Pérez, C.-M. Lehr, M. Hoffman, and P. Maincent, "Influences of process parameters on nanoparticle preparation performed by a double emulsion pressure homogenization technique," International Journal of Pharmaceutics, vol. 196, no. 2, pp. 177-182, 2000. 

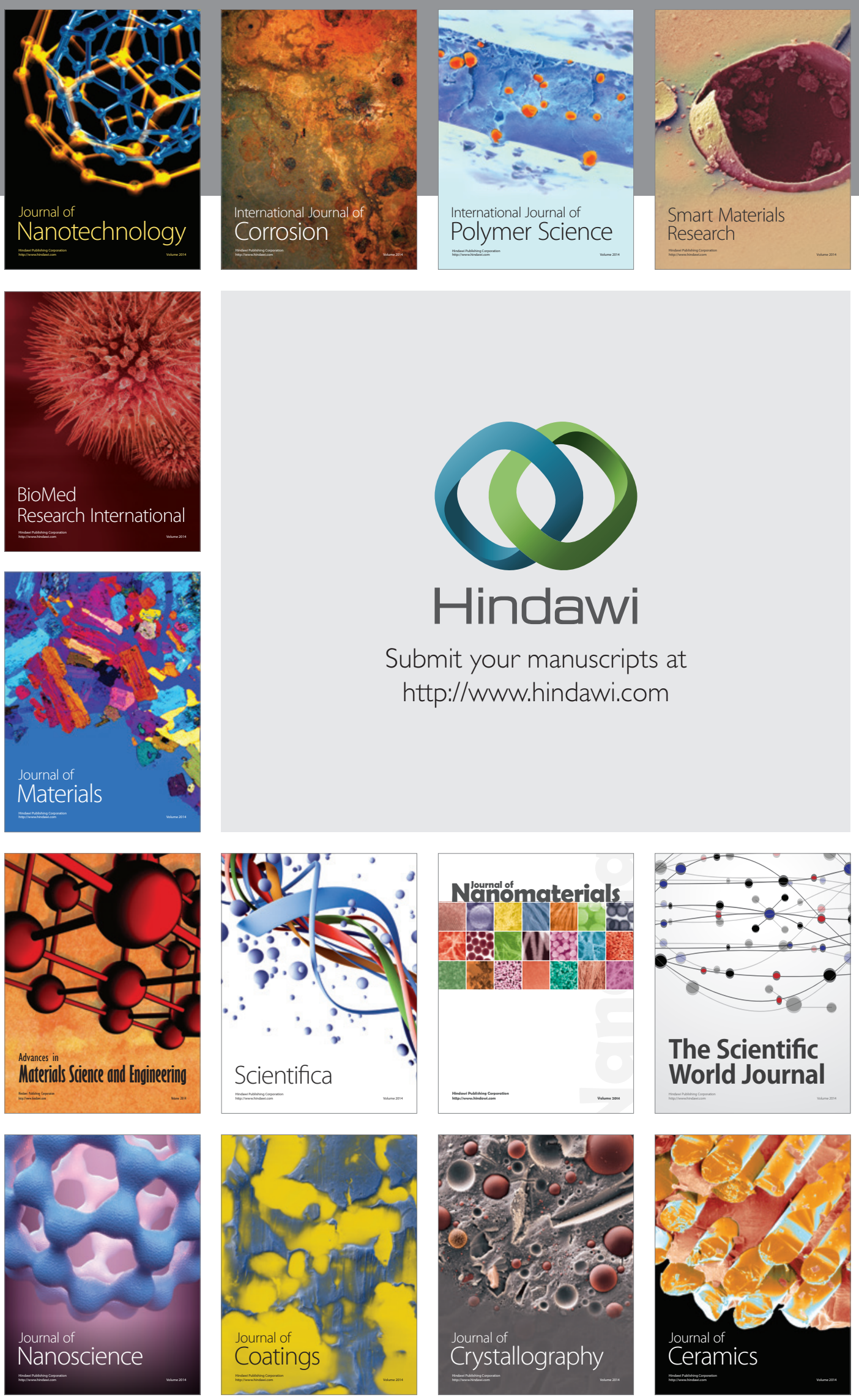

The Scientific World Journal

Submit your manuscripts at

http://www.hindawi.com

\section{World Journal}

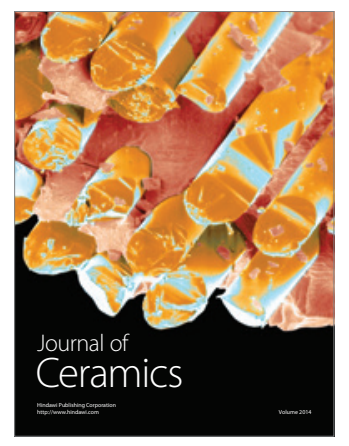

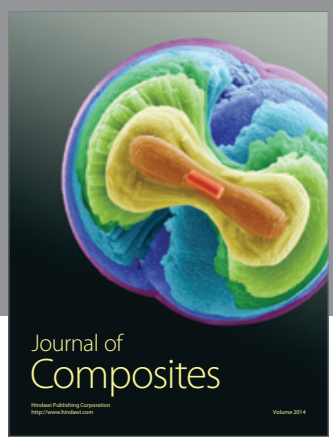
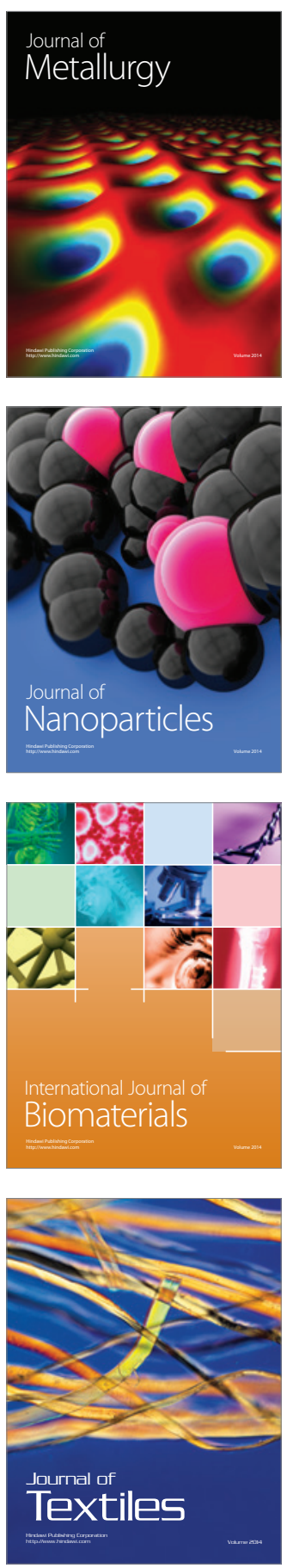